\title{
Integrated electrophysiological evaluation in early normal-tension glaucoma
}

Dario Messenioํㅜㄹ Giuseppe Marano², Elia Biganzoli²,3

${ }^{1}$ Eye Clinic, Department of Clinical Science, Luigi Sacco Hospital, University of Milan, Milan, Italy; ${ }^{2}$ Unit of Medical Statistics and Biometry, Fondazione IRCCS Istituto Nazionale dei Tumori, Milan, Italy; ${ }^{3}$ Department of Clinical Sciences and Community Health, University of Milan, Italy

\section{Abstract}

Purpose: To evaluate the variations of intraocular pressure (IOP), morphometric optic nerve head characteristic, perimetric indices and electrophysiological parameters (pattern electroretinogram and visual evoked potentials) before and after topical IOP lowering in patients with early normal-tension glaucoma.

Methods: we evaluated 38 eyes of 20 patients with IOP $<21 \mathrm{mmHg}$, initial glaucomatous optic neuropathy (valued with HRT: retinal nerve fiber layer thickness (RNFL) and linear cup/disk ratio (linear C/D ratio)), minimal visual field defects (Octopus 101: G2 program), best correct visual acuity more than 15/20 and pathological electrophysiological parameters (valued with pattern electroretinogram (PERG) and visual evoked potentials (VEPs)), free of systemic or other ocular diseases. All parameters were evaluated at the beginning of the study $\left(T_{0}\right)$ and after 12 months of therapy $\left(T_{12}\right)$. A randomized normal control group (27 eyes of 14 subjects) with apparent larger disc cupping underwent all exams at initial of study $\left(T_{0}\right)$ and after 12 months $\left(\mathrm{T}_{12}\right)$.

Results: Among electrophysiological parameters, at the beginning of the study NTG P100 VEPs latency is slightly increased and P100 amplitude is reduced compared to normal subjects. There are not significant variations after 12 months. P50 PERG latency in NTG is quite similar respect normal and do not modify after therapy. P50N95 complex PERG amplitude in NTG is reduced compared to normal subjects and slightly increases after 12 months (1.8 vs $1.5 ; 2.4$ vs 1.9 micronvolts, with different

Correspondence: Dario Messenio, via Domenichino 49, 20149 Milano, Italy.

E-mail:dmessenio@virgilio.it 
checkboard spatial frequency). Cortical retinal time (CRT) is slightly delayed in NTG and does not modify. Among visual field indices, MD and CLV is slightly higher in NTG and do not significantly modify after therapy. Among morphometric optic nerve head characteristics, linear C/D and RNFL thickness are quite similar in NTG and do not modify. IOP is quite similar between NTG and control group and modifies in NTG after therapy.

Conclusion: In a viewpoint of an integrated diagnostic, electrophysiological tests (VEPs and PERG) could provide a more sensitive measure of retinal ganglion cell integrity and help to distinguish between early normal-pressure glaucoma patients with no or minimal visual field alterations and normal subjects with apparent larger disc cupping.

Key words: early normal-tension glaucoma, initial glaucomatous optic neuropathy, minimal visual defects, pattern electroretinogram, visual evoked potentials

\section{A short guide to read electrophysiological parameters}

\subsection{Pattern electroretinogram (PERG)}

PERG represents an objective and direct measure of RGC function. It is a retinal biopotential evoked by a temporally modulated patterned stimulus (checkerboard or grating) of constant mean luminance. The waveform of the PERG depends on the temporal frequency of the stimulus. At low temporal frequencies $(<6$ reversal per second, equivalent to $3 \mathrm{~Hz}$ ) transient PERGs are obtained: PERG waveform in normal subjects usually consists of a small initial negative component with a peak time of 35 msec (N35), followed at 45-60 msec by a much larger positive component (P50), and a large negative component at about $95 \mathrm{msec}$ (N95). In glaucoma analysis, P50N95 complex amplitude (in micronvolt) and P50 implicit time (in $\mathrm{ms}$ ) are measured; this is done with different spatial frequency: either with checkboard subtending 30' of arc of visual angle or 15' (smaller).

\subsection{Visual evoked potentials (VEPs)}

VEPs characterize the state of the whole visual pathway. Also the waveform of the VEPs evoked by contrast reversal of pattern stimuli depends on the temporal frequency of the stimulus. The considerations are the same of these of PERG. At low temporal frequencies ( $<6$ reversal per second ( $r p s$ ) equivalent to $3 \mathrm{~Hz}$ ), transient VEPs are obtained: VEPs waveforms consist of a initial negative component with a peak time of approximately $75 \mathrm{msec}$ (N75), followed by a larger positive component (P100) at 100-110 msec and by a large negative component at 90-130 msec (N135). P100 latency (in msec) and amplitude (in micronvolt) are measured; this is done with different spatial frequency: either with checkboard subtending 30' of arc of visual angle or 15' (smaller). 


\section{Introduction}

Glaucoma is a multifactorial optic neuropathy characterized by progressive loss of retinal ganglion cells, changes in optic disk morphology and visual field defects. IOP is recognized as the most important risk factor for the development and/or progression of glaucomatous damage. ${ }^{1}$ A particular type of open-angle glaucoma, normal-tension glaucoma (NTG), has typical glaucomatous optic neuropathy evolution with diurnal IOP below $21 \mathrm{mmHg}$ without treatment. ${ }^{2,3}$ IOP reduction does not necessarily slow or halt disease progression. ${ }^{4}$

Pattern electroretinogram (PERG) is a useful tool for detection of open-angle glaucoma, but is not a routine diagnostic exam. It is a direct indicator of retinal ganglion cell function. ${ }^{5}$ PERG reflects diffuse RCG damage but not focal, ${ }^{6}$ so one should not necessarily find correlations between alterations of PERG and visual field. ${ }^{7}$ Up of $30 \%$ of retinal ganglion cells loss is associated with statistically significant changes in visual field sensitivity: ${ }^{8}$ visual field is not impaired in ocular hypertension $(\mathrm{OHT})$ or in early manifest glaucoma and therefore it is important to early diagnosis, before visual field defects are evident. PERG is altered in glaucoma and in many cases of $\mathrm{OHT},{ }^{9}$ even if in some case with OHT PERG may be normal. ${ }^{10}$ Several authors in human studies found PERG as a predictive value to identify those patients with elevated IOP who develop a glaucoma before visual field changes occur. ${ }^{11,12}$

PERG has higher sensibility to detect glaucomatous changes ${ }^{12,13}$ and it is abnormal in most patients with manifest disease. ${ }^{13,14}$ In some cases, PERG changes can precede detectable field losses because PERG is particularly sensitive to early damage. ${ }^{15}$

PERG reflects the total amount of electrophysiological activity of RGC, i.e., represents an objective and direct measure of RGC function. Analysing structure-function relationship in experimental and human studies, same authors suggest a hypothesis that may there be a stage of reversible dysfunction, that may be long, before RGCs dying. ${ }^{16}$ This dysfunction is potentially reversible and may be restored after IOP reduction ${ }^{17}$, not only in OHT or high-tension glaucoma, ${ }^{18}$ but also in NTG. ${ }^{17}$

Visual evoked potentials (VEPs) characterize the state of the whole visual pathway. In glaucomatous patients, there is a delay of P100 latency and/or P100 amplitude reduction. ${ }^{13}$ Moreover, cortical-retinal time (CRT), index of neural conduction in post-retinal visual pathways, derived by simultaneous recordings of VEPs and PERGs, i.e., latency difference between P50 PERG and P100 VEPs, is unchanged in $\mathrm{OHT}$, but increases as the diseases progresses and is correlated with reduction of PERG amplitude. Some of the earlier works have demonstrated a poor sensitivity of the VEP to detection of glaucomatous patients. ${ }^{19}$ Increased pattern VEP latency is significantly correlated with both the severity and location of visual field defects (particularly MD index) and the degree of cupping and pallor of the optic disc..$^{13,20,21}$ 
In this study, we evaluate functional (visual field indices; electrophysiological (VEPs and PERG) parameters) and morphometric optic nerve head characteristic, before and after topical IOP lowering in patients with early normal-tension glaucoma.

\section{Methods}

The study was approved by the Hospital Medical Ethics Committee, and informed consent was obtained from the subjects after explanation of the nature and possible consequences of the study. Health control subjects and patients with early stages of glaucoma were recruited from the eye clinics at Sacco Hospital of Milan (Italy).

\subsection{Patients with suspect normal-tension glaucoma}

Twenty subjects (38 eyes) with early normal-tension glaucoma were recruited. All patients underwent a complete clinical examination, Goldmann applanation tonometry, optic nerve head assessment, scanning laser tomography (Heidelberg Retina Tomograph - HRT), perimetry (Octopus 101: G2 program), VEPs and PERG recording at the beginning of the study $\left(T_{0}\right)$ and after 12 months $\left(T_{12}\right)$.

The inclusion criteria were: visual acuity more than $15 / 20$ with best correction; untreated IOP on a diurnal pressure curve lower than $21 \mathrm{mmHg}$ without treatment; initial glaucomatous optic neuropathy valued with HRT considering these inclusion criteria: one sector measurement labelled 'borderline' or 'outside of normal' at Moorfield Regression Analysis and two indices: RNFL less than 200, and linear C/D ratio more than 600; alteration of electrophysiological parameters: P50N95 PERG amplitude decreased or/and VEPS VEPs wave amplitude decreased; we consider as pathological if the values differ by less than two standard deviations from the correct normative value for age; visual field indices: MD and CLV, considering values 'borderline' or ' $1{ }^{\text {st }}$ Stage' of 'Glaucoma Staging System 2' perimetric staging. Exclusion criteria were: history of refractive surgery, high myopia, other ocular or systemic diseases, patients already in therapy or with other ocular or systemic diseases.

\subsection{Healthy subjects}

An age-matched control group of 14 healthy subjects (27 eyes) with the same morphometric optic nerve head characteristics (RNFL thickness less 200, and linear C/D ratio more than 600) but normal PERG, PEVs, and visual field indices; no ophthalmic diseases and no family history of glaucoma. Control group underwent a complete clinical examination at the beginning of the study $\left(T_{0}\right)$ and after 12 months $\left(T_{12}\right)$.

We analysed these two groups at the start of the study $\left(T_{0}\right)$ and after 12 months $\left(T_{12}\right)$. Glaucomatous patients underwent hypotonizing therapy with prostaglandins eye drops one drop a day, otherwise none therapy was done in control group. 


\subsubsection{Electroretinography}

Electrophysiological tests (VEPs and PERG) were recorded monocularly and simultaneously.

\subsubsection{Statistics}

The main aim of the statistical analysis is to quantify the diagnostic features of patients with early NTG and healthy subjects. Data were obtained from a sample of 38 eyes of patients $(n=20)$ with early NTG, and 27 eyes of healthy subjects ( $n$ = 14). The investigated variables are: latency and amplitude of P50N95 complex PERG wave and P100 VEP wave, with 30-minute and 15-minute checkerboard pattern stimulus; MD; CLV; RNFL thickness; linear C/D ratio; IOP; pachymetry. All the variables were recorded at $T_{0}$ and $T_{12}$, except pachymetry (only at $T_{0}$ ). CRT is defined as the difference between P100 VEPs wave and P50 PERG wave latencies.

The average values of the variables above were estimated, along with the following average differences: differences between eyes of NTG patients and healthy subjects, at $\mathrm{T}_{0}$ and at $\mathrm{T}_{12}$; differences between $\mathrm{T}_{12}$ and $\mathrm{T}_{0}$ for each of the two groups. To such end, mixed effects ANOVA methods were used. ${ }^{22}$ In each ANOVA model: (1) each variable is included as response variable; (2) time of measurement (start of study; 12 months later), group (NTG; healthy) is included as categorical predictor, with both simple effects and interaction effect; (3) to account for the correlation between measurements at distinct times (for each eye), and for the correlation between measurements of fellow eyes, two random effects, corresponding to subjects and eyes, respectively, are included. The results are reported in terms of estimated averages with respective 95\% confidence intervals, corrected with the Bonferroni rule. The analysis was performed using the software R 3.2.2, with the addition of the packages nlme and multcomp.

\section{Results}

Of the twenty patients with early NTG, 10 are female (50.0\%); the mean age is 67.6 years, with a standard deviation of 7.6 years. Of the fourteen healthy subjects, 11 are female (78.6\%); the mean age is 59.2 years, with a standard deviation of 13.1 years.

As reported in Table 1, positive average differences between eyes of NTG patients and healthy subjects emerge for VEP latencies. For P100/15 latencies, the differences are: $12.9 \mathrm{msec}$ (95\% Confidence interval: $(5.5,20.2) \mathrm{msec}$ ) at $\mathrm{T}_{0}$, and $10.5 \mathrm{msec}(95 \%$ C.I.: $(3.2,17.8) \mathrm{msec})$ at $\mathrm{T}_{12}$. For P100/30' latencies the differences are smaller: 8.9 msec (95\% C.I.: $(2.6,15.1) \mathrm{msec})$ at $\mathrm{T}_{0}$, and $8.8 \mathrm{msec}(95 \%$ C.I.: $(2.5,15.0) \mathrm{msec})$. For amplitude measurements, negative differences between NTG and healthy subjects emerge at $\mathrm{T}_{0}$ and $\mathrm{T}_{12}$, both for P100 VEP wave and P50N95 complex PERG amplitudes. For CRT, there are positive differences, both at $T_{0}$ and at $T_{12}$.

An average increase in the period between $T_{0}$ and $T_{12}$ of P50 PERG amplitudes 
Table 1. Estimated average values and differences of electrophysiological parameters.

\begin{tabular}{|c|c|c|c|c|}
\hline & \multicolumn{2}{|c|}{ Estimated average values } & \multicolumn{2}{|c|}{ Estimated average differences } \\
\hline & $\begin{array}{l}\text { NTG } \\
\text { Est (95\% C.I.) }\end{array}$ & $\begin{array}{l}\text { Healthy } \\
\text { Est }(95 \% \text { C.I.) }\end{array}$ & $\begin{array}{l}\text { NTG vs Healthy : } \\
\text { Est ( } 95 \% \text { corr. C.I.) }\end{array}$ & $\begin{array}{l}T_{12} \text { vs } T_{0}: \\
\text { Est ( } 95 \% \text { corr. C.I.) }\end{array}$ \\
\hline $\begin{aligned} \mathrm{L}^{100 / 15^{\prime}}: & \text { at } \mathrm{T}_{0} \\
& \text { at } \mathrm{T}_{12}\end{aligned}$ & $\begin{array}{l}124.1(120.4,127.8) \\
122.3(118.7,126.0)\end{array}$ & $\begin{array}{l}111.2(106.8,115.6) \\
111.9(107.5,116.3)\end{array}$ & $\begin{array}{l}\text { at } T_{0}: 12.9(5.5,20.2) \\
\text { at } T_{12}: 10.5(3.2,17.8)\end{array}$ & $\begin{array}{l}\text { NTG: }-1.7(-4.0,0.5) \\
\text { Healthy: } 0.6(-0.4,1.7)\end{array}$ \\
\hline $\begin{aligned} \text { L100/30' : } & \text { at } T_{0} \\
& \text { at } T_{12}\end{aligned}$ & $\begin{array}{l}114.3(111.2,117.5) \\
114.8(111.6,117.9)\end{array}$ & $\begin{array}{l}105.4(101.7,109.2) \\
106.0(102.2,109.8)\end{array}$ & $\begin{array}{l}\text { at } \mathrm{T}_{0}: 8.9(2.6,5.1) \\
\text { at } \mathrm{T}_{12}: 8.8(2.5,15.0)\end{array}$ & $\begin{array}{l}\text { LNG : } 0.5(-1.5,2.5) \\
\text { Healthy : } 0.6(-1.8,3.0)\end{array}$ \\
\hline 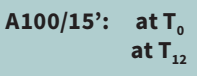 & $\begin{array}{l}8.2(6.5,9.9) \\
9.0(7.3,10.8)\end{array}$ & $\begin{array}{l}14.6(12.6,16.7) \\
14.5(12.5,16.6)\end{array}$ & $\begin{array}{l}\text { at } \mathrm{T}_{0}:-6.4(-9.8,-3.0) \\
\text { at } \mathrm{T}_{12}:-5.5(-8.9,-2.1)\end{array}$ & $\begin{array}{l}\text { NTG : } 0.9(-0.1,1.8) \\
\text { Healthy : }-0.1(-1.2,1.1)\end{array}$ \\
\hline $\begin{aligned} A 100 / 30 & \text { at } T_{0} \\
& \text { at } T_{12}\end{aligned}$ & $\begin{array}{l}8.2(6.5,10.0) \\
8.4(6.7,10.1)\end{array}$ & $\begin{array}{l}13.6(11.6,15.7) \\
14.5(12.4,16.5)\end{array}$ & $\begin{array}{l}\text { at } \mathrm{T}_{0}:-5.4(-8.9,-2.0) \\
\text { at } \mathrm{T}_{12}:-6.1(-9.5,-2.6)\end{array}$ & $\begin{array}{l}\text { NTG : } 0.2(-0.8,1.2) \\
\text { Healthy : } 0.8(-0.3,2.0)\end{array}$ \\
\hline $\begin{array}{ll}\text { L50/15': }^{\prime} & \text { at T } \\
& \text { at } T_{12}\end{array}$ & $\begin{array}{l}62.1(59.7,64.4) \\
60.7(58.3,63.0)\end{array}$ & $\begin{array}{l}60.1(57.4,62.9) \\
58.0(55.2,60.8)\end{array}$ & $\begin{array}{l}\text { at } T_{0}: 1.9(-2.7,6.5) \\
\text { at } T_{12}: 2.7(-1.9,7.3)\end{array}$ & $\begin{array}{l}\text { NTG : }-1.4(-5.3,2.5) \\
\text { Healthy : }-2.1(-6.7,2.5)\end{array}$ \\
\hline $\begin{array}{ll}\text { L50/30': } & \text { at } T_{0} \\
& \text { at } T_{12}\end{array}$ & $\begin{array}{l}57.8(55.7,59.9) \\
56.4(54.2,58.5)\end{array}$ & $\begin{array}{l}56.5(54.0,59.1) \\
55.8(53.3,58.4)\end{array}$ & $\begin{array}{l}\text { at } \mathrm{T}_{0}: 1.2(-3.0,5.5) \\
\text { at } \mathrm{T}_{12}: 0.5(-3.7,4.7)\end{array}$ & $\begin{array}{l}\text { NTG }-1.4(-4.6,1.8) \\
\text { Healthy : }-0.7(-4.5,3.1)\end{array}$ \\
\hline $\begin{array}{ll}A 50 / 15^{\prime}: & \text { at } T_{0} \\
& \text { at } T_{12}\end{array}$ & $\begin{array}{l}1.5(1.2,1.7) \\
1.8(1.6,2.1)\end{array}$ & $\begin{array}{l}2.4(2.1,2.6) \\
2.5(2.2,2.8)\end{array}$ & $\begin{array}{l}\text { at } T_{0}:-0.9(-1.4,-0.4) \\
\text { at } T_{12}:-0.7(-1.1,-0.2)\end{array}$ & $\begin{array}{l}\text { NTG : } 0.3(0.1,0.6) \\
\text { Healthy : } 0.1(-0.2,0.5)\end{array}$ \\
\hline $\begin{array}{ll}\mathrm{A50} / 30^{\prime}: & \text { at } \mathrm{T}_{0} \\
& \text { at } \mathrm{T}_{12}\end{array}$ & $\begin{array}{l}1.9(1.6,2.2) \\
2.4(2.1,2.6)\end{array}$ & $\begin{array}{l}2.7(2.4,3.0) \\
2.9(2.6,3.3)\end{array}$ & $\begin{array}{l}\text { at } \mathrm{T}_{0}:-0.8(-1.3,-0.3) \\
\text { at } \mathrm{T}_{12}:-0.6(-1.1,0.0)\end{array}$ & $\begin{array}{l}\text { NTG : } 0.5(0.2,0.8) \\
\text { Healthy : } 0.3(-0.1,0.6)\end{array}$ \\
\hline $\begin{array}{ll}\text { CRT/15': } & \text { at } T_{0} \\
& \text { at } T_{12}\end{array}$ & $\begin{array}{l}61.8(58.2,65.4) \\
61.5(57.9,65.1)\end{array}$ & $\begin{array}{l}51.1(46.8,55.4) \\
53.9(49.6,58.2)\end{array}$ & $\begin{array}{l}\text { at } \mathrm{T}_{0}: 10.7(3.5,17.9) \\
\text { at } \mathrm{T}_{12}: 7.6(0.4,14.8)\end{array}$ & $\begin{array}{l}\text { NTG : }-0.3(-4.6,3.9) \\
\text { Healthy : } 2.8(-2.3,7.9)\end{array}$ \\
\hline $\begin{array}{ll}\text { CRT/30': } & \text { at } T_{0} \\
& \text { at } T_{12}\end{array}$ & $\begin{array}{l}61.8(58.2,65.4) \\
61.5(57.9,65.1)\end{array}$ & $\begin{array}{l}51.1(46.8,55.4) \\
53.9(49.6,58.2)\end{array}$ & $\begin{array}{l}\text { at } T_{0}: 7.6(0.6,14.6) \\
\text { at } T_{12}: 8.2(1.2,15.2)\end{array}$ & $\begin{array}{l}\text { NTG : } 1.9(-2.0,5.8) \\
\text { HEalthy : } 1.3(-3.3,5.8)\end{array}$ \\
\hline
\end{tabular}

NTG: eyes of patients with early normal-tension glaucoma; Healthy: eyes of healthy subjects. Electrophysiological parameters: L100 and L50: latency of P100 VEP and P50 PERG waves respectively; A100 and A50: amplitude of P100 VEP and P50N95 complex PERG waves. The text: /15' and /30' indicate measurements taken with 15-minutes and 30-minutes checkerboard pattern stimulus, respectively.

emerges only for the NTG group. The estimates are: $0.3 \mu \mathrm{V}(95 \%$ C.I.: $(0.1,0.6) \mu \mathrm{V})$ for the P50/15' amplitude and $0.5 \mu \mathrm{V}(95 \%$ C.I.: $(0.2,0.8) \mu \mathrm{V})$ for the P50/30' amplitude. No relevant difference emerges for the remainder electrophysiological measurements.

Concerning the visual field indices (Table 2): for mean defect (MD), a positive average difference between NTG and healthy subjects groups emerges at $\mathrm{T}_{0}: 1.7 \mathrm{~dB}$ (95\% C.I.: $(0.5,3.0) \mathrm{dB})$. Also, a positive difference between the groups is evidenced for CLV at $\mathrm{T}_{12}: 2.8 \mathrm{~dB}(95 \%$ C.I.: $(0.6,4.9) \mathrm{dB})$. For IOP, at $\mathrm{T}_{0}$ the difference between NTG and healthy subjects is not relevant. Then, a reduction of IOP between $T_{0}$ and $\mathrm{T}_{12}$ emerges in the NTG group only: $-5.2 \mathrm{mmHg}(95 \%$ C.I.: $(-5.9,-4.4) \mathrm{mmHg})$. In 
Table 2. Estimated average values and differences of visual field indices

\begin{tabular}{|c|c|c|c|c|}
\hline & $\begin{array}{l}\text { NTG } \\
\text { Est }(95 \% \text { C.I.) }\end{array}$ & $\begin{array}{l}\text { Healthy } \\
\text { Est }(95 \% \text { C.I.) }\end{array}$ & $\begin{array}{l}\text { NTG vs Healthy : } \\
\text { Est ( } 95 \% \text { corr. C.I.) }\end{array}$ & $\begin{array}{l}T_{12} \text { vs } T_{0}: \\
\text { Est ( } 95 \% \text { corr. C.I.) }\end{array}$ \\
\hline $\begin{array}{l}\text { MD : } \\
\text { at } T_{0} \\
\text { at } T_{12}\end{array}$ & $\begin{array}{l}3.3(2.7,3.9) \\
3.2(2.6,3.9)\end{array}$ & $\begin{array}{l}1.5(0.8,2.3) \\
2.2(1.4,2.9)\end{array}$ & $\begin{array}{l}\text { at } \mathrm{T}_{0}: 1.7(0.5,3.0) \\
\text { at } \mathrm{T}_{12}: 1.1(-0.2,2.3)\end{array}$ & $\begin{array}{l}\text { NTG : }-0.1(-0.6,0.5) \\
\text { Healthy: } 0.6(0.0,1.2)\end{array}$ \\
\hline $\begin{array}{l}\text { CLV : } \\
\text { at } T_{0} \\
\text { at } T_{12}\end{array}$ & $\begin{array}{l}3.9(2.8,5.0) \\
4.8(3.8,5.9)\end{array}$ & $\begin{array}{l}2.0(0.7,3.3) \\
2.1(0.8,3.3)\end{array}$ & $\begin{array}{l}\text { at } T_{0}: 1.9(-0.2,4.0) \\
\text { at } T_{12}: 2.8(0.6,4.9)\end{array}$ & $\begin{array}{l}\text { NTG : } 0.9(-0.1,1.9) \\
\text { Healthy: } 0.1(-1.1,1.3)\end{array}$ \\
\hline $\begin{array}{l}\text { Lin.C|D : } \\
\text { at } T_{0} \\
\text { at } T_{12}\end{array}$ & $\begin{array}{l}641.1(601.7,680.5) \\
640.9(601.5,680.4)\end{array}$ & $\begin{array}{l}703.8(656.8,750.8) \\
702.9(655.9,749.9)\end{array}$ & $\begin{array}{l}\text { at } T_{0}:-62.7(-140.9,15.5) \\
\text { at } T_{12}:-62.0(-140.2,16.2)\end{array}$ & $\begin{array}{l}\text { NTG : }-0.2(-21.2,20.8) \\
\text { Healthy : }-0.9(-25.8,24.1)\end{array}$ \\
\hline $\begin{array}{l}\text { RNFL: } \\
\text { at } T_{0} \\
\text { at } T_{12}\end{array}$ & $\begin{array}{l}188.2(167.9,208.4) \\
181.7(161.4,202.0)\end{array}$ & $\begin{array}{l}202.8(178.7,227.0) \\
198.8(174.6,222.9)\end{array}$ & $\begin{array}{l}\text { at } \mathrm{T}_{0}:-14.7(-54.9,25.5) \\
\text { at } \mathrm{T}_{12}:-17.1(-57.3,23.1)\end{array}$ & $\begin{array}{l}\text { NTG : }-6.5(-19.2,6.3) \\
\text { Healthy : }-4.1(-19.2,11.0)\end{array}$ \\
\hline $\begin{array}{l}\text { IOP: } \\
\text { at } T_{0} \\
\text { at } T_{12}\end{array}$ & $\begin{array}{l}17.5(16.5,18.5) \\
12.3(11.3,13.3)\end{array}$ & $\begin{array}{l}15.7(14.5,16.9) \\
15.5(14.3,16.7)\end{array}$ & $\begin{array}{l}\text { at } \mathrm{T}_{0}: 1.8(-0.2,3.7) \\
\text { at } \mathrm{T}_{12}:-3.2(-5.2,-1.3)\end{array}$ & $\begin{array}{l}\text { NTG : }-5.2(-5.9,-4.4) \\
\text { Healthy : }-0.2(-1.1,0.7)\end{array}$ \\
\hline $\begin{array}{l}\text { PAC : } \\
\text { at } T_{0}\end{array}$ & $572.5(555.2,589.9)$ & $549.6(528.8,570.3)$ & at $\mathrm{T}_{0}: 23.0(-4.0,50.0)$ & - \\
\hline
\end{tabular}

NTG: eyes of patients with early normal-tension glaucoma; Healthy: eyes of healthy subjects. Visual field indices: MD: mean defect; CLV = correct loss variance. Morphometric parameters: RNFL: RNFL thickness; lin.C/D = linear C/D. IOP: intraocular pressure. PAC: pachimetry.

agreement with this result, at $\mathrm{T}_{12}$ a negative difference between NTG and healthy subjects is found: $-5.2 \mathrm{mmHg}(95 \%$ C.I.: $(-5.9,-4.4) \mathrm{mmHg}$ ). No sensible difference is found for the remainder variables.

\section{Discussion}

The most important problem for the correct therapy of glaucoma is the early diagnosis. Precocious diagnosis is more difficult in normal-tension glaucoma because IOP values are apparently normal, ${ }^{23}$ even if larger disks seem to be more susceptible to IOP-related stress. Eyes with NTG have a significantly thinner lamina cribrosa and so undergoes significant displacement due to IOP, according to mathematical finite element modelling. ${ }^{3,24}$

Among diagnostic exams, electrophysiological tests, as VEPS and PERG, can be used to quantify retinal ganglion cells function. Some authors ${ }^{17,18,25}$ indicate that the abnormal PERG recorded in eyes with early stages of glaucoma may often improve after IOP reduction. According to these authors, retinal ganglion cells undergo a prolonged period of dysfunction and degeneration before cell loss; PERG (particularly P50N95 complex amplitude) can evaluate this dysfunction, that may be 
restored after IOP reduction, not only in OHT but also in glaucoma patients, and in NTG glaucoma. To have a substantial improvement, the PERG must be abnormal: no significant changes occurred in acetazolamide-treated normal subjects, despite an IOP reduction of approximately $30 \% .{ }^{26}$ In NTG it improves also after smaller IOP reductions because NTG eyes have a lower functional threshold. ${ }^{16}$ Finally, PERG improvement is very little in patients with advanced glaucoma because the number of ganglion cell loss is higher and therefore the functional recovery is small. ${ }^{26}$

In NTG there is only an electrophysiological study: Lestak found remarkable P100 VEPs amplitude reduction, while PERG was almost unaffected. ${ }^{27}$

In our study on early NTG patients, P100 VEPs amplitude is reduced, according to Lestak, ${ }^{27}$ and $\mathrm{P} 100$ latency is slightly delayed. After therapy, these PEV parameters do not significantly modify: this is understandable because it is unlikely that a topical therapy may have some effect on the functionality (strictly neurological) of the visual pathways. P50N95 complex PERG amplitude at the beginning of study $\left(T_{0}\right)$ is reduced compared to the control group and slightly arise after IOP lowering: these results suggest that there could be a correlation between IOP and PERG changes.

IOP reduces significantly even if the baseline IOP is slightly higher than 15.5 $\mathrm{mmHg}$ and this confirms that those patients have NTG, as explained above. The reduction of IOP is correlated to the effective presence of a glaucoma: hyponizing normal eyes don't modify P50N95 complex PERG amplitude at all ${ }^{15}$. So an increase of amplitude of P50N95 complex PERG following to a decrease of IOP is suggestive of a dysfunction in a suspect or early glaucoma (in this study, NTG), dysfunction that could be (partially) restored after hyponizing. ${ }^{16}$

Morphometric optic nerve head characteristics don't modify after therapy, and also visual field indices. This indicates that the papillary morphometric nerve head parameters and the classic functional (perimetric) are not sensitive to detect improvements secondary to hypotonic therapy.

A limitation of this study could be to not have included patients with the disease even at more advanced stages. In fact, considering multiple levels of NTG progression would enable to check more exhaustively the extent of functional recovery in later stages.

\section{Conclusion}

Our pilot study is the first study trying to individuate and differentiate with electrophysiological tests normal patient with apparent larger disc cupping and early NTG ones with still quite normal visual field or minimal visual field defect. ${ }^{23}$ This diagnostic approach may provide an important information to avoid starting useless therapy, or, on the contrary, to start precociously hypotonizing therapy in NTG before visual field occurs. 


\section{References}

1. Heijl A, Leske MC, Bengtsson B, Hyman L, Hussein M. Reduction of intraocular pressure and glaucoma progression: results from the early manifest glaucoma trial. Arch Ophthalmol 2002;120(10):12681279.

2. Krupin T. Special considerations in low-tension glaucoma. Can J Ophthalmol 2007;42(3):414-417.

3. Hayamizu F, Yamazaki Y, Nakagami T, Mizuki K. Optic disc size and progression of visual field damage in patients with normal-tension glaucoma. Clin Opthalmol 2013;7:807-813.

4. Anderson DR, Drance SM, Schulzer M. Collaborative normal-tension glaucoma study group. Factors that predict the benefit of lowering intraocular pressure in normal-tension glaucoma. Am J Ophthalmol 2003;136(5):820-829.

5. Maffei L, Fiorentini A. Electroretinographic responses to alternating gratings before and after section of the optic nerve. Science 1981;211(4485):953-955.

6. Bach M, Hoffmann MB. Update on the Pattern Electroretinogram in Glaucoma. Optom Vis Sci 2008;85(6):386-395.

7. Bach M, Sulimma F, Gerling J. Little correlation of the pattern electroretinogram (PERG) and visual filed measures in early glaucoma. Doc Ophthalmol 1997-1998;94(3):253-263.

8. Quigley HA, Addicks EM, Green WR. Optic nerve damage in human glaucoma. III Quantitative correlation of nerve fiber loss and visual field defect in glaucoma, ischemic neuropathy, papilledema and toxic neuropathy. Arch Ophthalmol 1982;100(1):135-146.

9. Price MJ, Drance SM, Price M, Schulzer M, Douglas GR, Tansley B. The pattern electroretinogram and visual-evoked potential in glaucoma. Greafes Arch Clin Exp Ophthalmol 1988:226:542-547.

10. Bielik M, Zwas F, Shin DH, Tsai CS. PERG and spectral sensitivity in ocular Hypertensive and chronic open-angle glaucoma patients. Graefes Arch Clin Exp Ophthalmol 1991;229(5):401-405.

11. Gonzalvo Ibanes FJ, Fernandez Tirado FJ, Almarcegui Lafita C, et al. Predictive value of the pattern-electroretinogram in glaucoma. Arch Soc Esp Oftalmol 2001;76(8):485-491.

12. Bach M, Unsoeld AS, Philippin $\mathrm{H}$, et al. Pattern ERG as an early indicator in ocular hypertension: a long-term prospective study. Invest Ophthalmol Vis Sci 2006;47(11):4881-4887.

13. Parisi V, Miglior S, Manni G, Centofanti M, Bucci M. Clinical ability of pattern electroretinograms and visual evoked potentials in detecting visual dysfunction in ocular hypertension and glaucoma. Ophthalmology 2006;113(2):216-228.

14. Bayer AU, Maag KP, Erb C. Detection of optic neuropathy in glaucomatous eyes with normal standard visual fields using a test battery of short-wavelength automated perimetry and pattern electroretinography. Opthalmology 2002;109(7):1350-1361.

15. Hood DC, Xu L, Thienprasiddhi P, et al. The pattern electroretinogram in glaucoma patients with confirmed visual field deficit. Invest Opthalmol Vis Sci 2005;46(7):2411-2418.

16. Ventura LM, Porciatti DS. Restoration of retinal ganglion cell function in early glaucoma after intraocular pressure reduction. A pilot study. Ophthalmology 2005;112(1):20-27.

17. North RV, Jones AL, Drasdo N, Wild JM, Morgan JE. Electrophysiological evidence of early functional damage in glaucoma and ocular hypertension. Inv Ophthalmol Vis Sci 2010;51(2):1216-1222.

18. Ventura LM, Porciatti V. Pattern electroretinogram in glaucoma. Curr Opin Ophthalmol 2006;17(2):196-202.

19. Mitchell KW, Howe JW, Spencer SR. Visual evoked potentials in the older population: age and gender effects. Clin Phys Physiol Meas 1987;8(4):317-324.

20. Towle VL, Moskowitz A, Sokol S, Schwartz B. The visual evoked potential in glaucoma and ocular hypertension: effects of check size, field size, and stimulation rate. Inv Ophthalmol Vis Sci 1983;24(2),175-183.

21. Kothari R, Bokariya P, Singh S, Singh R. Significance of Visual Evoked Potentials in the Assessment of Visual Field Defects in Primary Open-Angle Glaucoma: A Review. Neurosci J 2013;2013:418320.

22. Murdoch IE, Morris SS, \& Cousens SN: People and eyes: statistical approaches in ophthalmology. $\mathrm{Br}$ J Ophthalmol 1998;82(8):971-973. 
23. Jonas JB, Sturmer J, Papastathopoulos KI, Meier-Gibbsons F, Dichtl A. Optic disc size and optic nerve damage in normal pressure glaucoma. Br J Ophthalmol 1995;79(12):1102-1105.

24. Bellezza AJ, Hart RT, Burgoyne CF. The optic nerve head as a biomechanical structure: initial finite element modeling. Invest Ophthal Vis Sci 2000;41(10):2991-3000.

25. Ventura LM, Porciatti V, et al. Pattern electroretinogram abnormality and glaucoma. Ophtalmology 2005;112(1):10-19.

26. Tuulonen A, Lehtola J, Airaksinen PJ. Nerve fiber layer defects with normal visual field: do normal optic disc and normal visual field indicate absence of glaucomatous abnormality? Ophthalmology 1993;100(5):587-597.

27. Lestak J, Nutterova Elena, Pitrova Sarka, et al. High tension versus normal-tension glaucoma. A comparison of structural and functional examinations. J Clinic Experiment Ophthalmol 2012; S5:006. doi:10.4172/2155-9570.S5-006. 